\title{
Use of an acoustic wave sensor to follow lead absorption by porcine skin
}

\author{
Marta I.S. Veríssimo $^{a}$, Alberto A.C.C. Pais ${ }^{b}$, João A.B.P. Oliveira ${ }^{a}$, M. Teresa S.R. Gomes ${ }^{a}, *$ \\ a Department of Chemistry, University of Aveiro, 3810-193 Aveiro, Portugal \\ b Department of Chemistry, University of Coimbra, 3004-535 Coimbra, Portugal \\ Received 14 July 2006; received in revised form 5 June 2007; accepted 2 July 2007
}

Available online 7 July 2007

\begin{abstract}
A new acoustic wave sensor capable of detecting and quantifying lead is presented, and fully characterized in terms of sensitivity, selectivity, and linear calibration range. The sensor was used to quantify lead absorption by pig stratum corneum and to follow in real time, both the absorption and desorption of lead by the skin. Values of lead absorption of $29.6 \mathrm{mg} \mathrm{Pb} / \mathrm{g}$ of stratum corneum were obtained. Lead in solution was also quantified by atomic absorption spectrometry (AAS). The results obtained by both methods, AAS and the sensor, were compared and no statistical differences in the accuracy and precision of the results were found.
\end{abstract}

(C) 2007 Elsevier B.V. All rights reserved.

Keywords: Bulk acoustic wave sensor; Lead; Stratum corneum

\section{Introduction}

Lead is toxic, and lead poisoning darkened the history of several civilizations. The fall of Roman Empire has been attributed to massive poisoning of the population of Rome by lead from plumbing, reducing drastically the health and longevity of Roman citizens. High levels of lead have also been found in Egyptian mummies. Some reports also attribute Van Gogh's madness to lead poisoning, arising from the ingestion of pigments containing lead during the process of wetting brushes within his mouth.

Although lead is now avoided in plumbing, it is still used in a variety of everyday artefacts and also in protective shields, and not only by Superman. Lead can enter the body by ingestion, inhalation, but also through the skin. Both organic and inorganic lead salts can be absorbed by the skin, and lead that passes through the skin partitions strongly into the extracellular fluid. Skin is considered to be the largest organ in our body, and it is composed of three layers, the epidermis, the dermis and subcutaneous fat.

The epidermis is the outer most layer of the skin, and as an interface with the surroundings, it plays an important role in protecting against pathogens. Epidermis is divided into five sub-

\footnotetext{
* Corresponding author. Tel.: +351 234370722; fax: +351 234370084.

E-mail address: mtgomes@dq.ua.pt (M.T.S.R. Gomes).
}

layers [1] or strata, namely, stratum corneum, stratum lucidum, stratum granulosum, stratum spinosum and stratum germinativum, also called stratum basale. Therefore, the protection of the skin is provided primarily by the stratum corneum, and percutaneous absorption is regulated by diffusion across this superficial region only $10-20 \mu \mathrm{m}$ thick [1]. The permeability properties of the stratum corneum are unchanged by removal from the body and therefore in vitro experiments are appropriate [2]. Since pig skin structure is very similar to that of humans, it is very often the species of choice for in in vitro percutaneous absorption studies $[3,4]$.

Lead has for long been quantified by atomic absorption spectrophotometry (AAS) [5], with flame atomization, or whenever quantification levels are insufficient, with electrothermal atomization. Atomic absorption spectrophotometers are bulky and expensive instruments, although even more expensive instruments, like inductively coupled plasma atomic emission spectrometers have been used, mainly when multiple elements need to be analysed. Portable ion selective electrodes can also be used [6], which respond to the logarithm of activity rather than lead concentration and cannot be used without a reference electrode. Anodic stripping voltammetry has conquered its own place in the determination of lead in environmental samples due the electrochemical preconcentration step. A three electrode system is necessary, and new working electrodes have been recently reported for use in adsorptive stripping voltammetry, in which selective preconcentration of metal ions occurs in open circuit 
conditions [7,8]. Medium exchange to pure electrolyte solution is required for the voltammetric quantification of the metal ions and polishing of the electrode to assure a fresh surface exposure is also often necessary.

Acoustic wave sensors based on piezoelectric quartz crystals are known for their simplicity and low cost as well as for their reliability whenever carefully designed. They have been used for metal analysis [9] and recently, a biosensor for lead has been reported [10]. This new acoustic wave biosensor presents serious drawbacks, as it is extremely $\mathrm{pH}$ sensitive, regeneration step is very long $(2 \mathrm{~h})$, and selectivity maybe questionable, and it is not addressed in the paper.

In this work, a new quartz acoustic wave sensor for lead is reported. Fast reversibility is demonstrated and membrane optimization regarding selectivity over some other cations has been undertaken. This new sensor is then applied to lead absorption studies. The top layer of the epidermis from pig, stratum corneum (SC), was put in contact with a lead solution and the sensor was used to follow lead absorption by the skin in real time. The quantity of lead absorbed by the skin was then calculated.

Lead from skin was released in contact with pure Milli-Q water. Kinetics of the transfer of lead between the skin and water was possible to follow with the new methodology proposed here.

After both absorption and desorption experiments, the liquid content of the cell, where experiments have been performed, was also analysed by atomic absorption spectrometry (AAS).

\section{Experimental}

\subsection{Reagents}

The membranes were prepared with polyvinyl chloride (PVC, Fluka 81388), and $o$-nitrophenyloctyl ether (NPOE, Fluka 73732) as plasticizer. The lead ionophore was 4-tert-butylcalix [4] arene-tetrakis(thioacetic acid-dimethylamide) (Fluka 15343). To some of these membranes potassium tetrakis $(p$ chlorophenyl)borate (KTpClPB, Fluka 60591) was added.

For atomic absorption spectrometry standard solutions were prepared with lead standard solution $1000 \mathrm{mg} / \mathrm{L}$ (BDH 14036), while for the sensor a lead stock solution of approximately $1000 \mathrm{mg} / \mathrm{L}$ was prepared by weighing the appropriate amount of the pure dried solid lead nitrate (Riedel-deHaën 31137). The exact concentration was found after AAS analysis and standard solutions were prepared by dilution.

\subsection{Apparatus}

For the lead membrane characterization a flow injection analysis (FIA) methodology, where water carries the metal solution to the crystal cell, was used. The experimental setup was described elsewhere [11]. The frequencies of oscillation of the crystal were, in the experiments, monitored with a frequency counter Leader LCD-823A.

A batch methodology was developed for lead absorption from skin. Fig. 1 shows the experimental setup used. The crystal was inserted in a teflon cell, that was attached to a thermostated glass cell, where solutions were kept at $36.5^{\circ} \mathrm{C}$. The coated face of

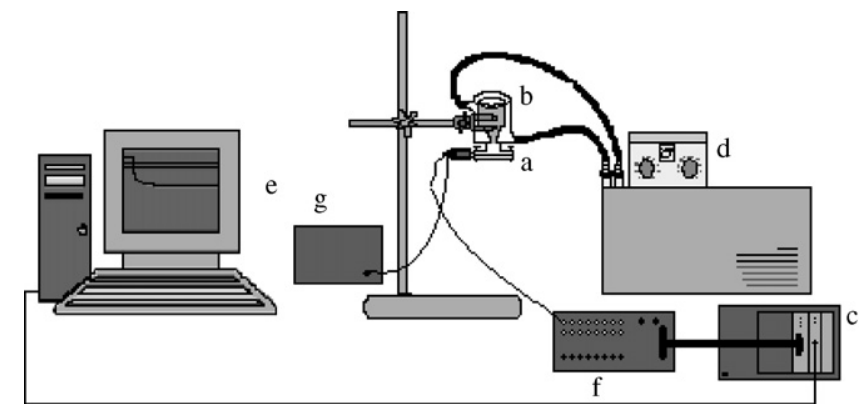

Fig. 1. Experimental layout: (a) crystal cell; (b) thermostated cell; (c) counter/timer device PXI 6608; (d) thermostated bath; (e) personal computer; (f) BNC 2121 connector block; (g) power source.

the crystal was in contact with the solution. The glass cell was kept closed with parafilm to prevent solution evaporation.

Oscillators and cells were home-made and the frequencies of oscillation of the crystals were monitored with a Counter/Timer Device PXI 6608 from National Instruments and recorded on a PC, with data acquisition software written in Lab View.

For atomic absorption analysis a Perkin-Elmer A Analyst 100 atomic spectrometer was used.

\subsection{Procedure used in membrane composition optimization}

Membranes were prepared after weighing the appropriate amount of PVC, plasticizer, ionophore and lipophilic salt, which were dissolved in tetrahydrofuran.

Several crystals were prepared with membranes of different compositions, at first with different PVC/NPOE ratios, and then adding different lipophilic salt contents. The coated crystals were then allowed to dry for $48 \mathrm{~h}$, after which one of them was inserted into the cell. Only the coated face was exposed to the flowing stream of water.

Fixed quantities of $0.5 \mathrm{~mL}$ of lead solutions of several concentrations were injected. The differences in the frequency of the crystal before injection, while Milli-Q water was flowing through the cell, and the minimum frequency observed after each sample injection, were computed. After each sample, a complete recover of the initial frequency of the crystal was achieved in less than $2 \mathrm{~min}$, and no sample was injected before a constant reading, corresponding to the baseline frequency was attained.

Selectivities of the several membranes were evaluated by the fixed interference method, recording the frequency decrease obtained injecting lead solutions with fixed quantities of possible interfering metals. Metals tested included $\mathrm{Na}, \mathrm{Ca}, \mathrm{Cd}, \mathrm{Cu}$, $\mathrm{K}, \mathrm{Mn}, \mathrm{Zn}, \mathrm{Mg}$ and $\mathrm{Al}$.

\subsection{Procedure used in skin sorption experiments}

After choosing the best membrane composition, the coated crystal was inserted into the thermostated cell. A working temperature of $36.5^{\circ} \mathrm{C}$ was chosen throughout this work. Ten milliliters of Milli-Q water were introduced into the glass cell, which were kept undisturbed until constant frequency readings were achieved. Ten microliters of lead standard $1000 \mathrm{mg} / \mathrm{L}$ were then introduced, which produced a frequency decrease. Succes- 
Table 1

Sensitivity of sensors coated with several NPOE/PVC ratios

\begin{tabular}{llllllllll}
\hline & \multicolumn{1}{l}{ NPOE/PVC } & & & & & \\
\cline { 2 - 9 } & $1 / 3$ & $1 / 2$ & $1 / 1$ & $3 / 2$ & $2 / 1$ & $5 / 2$ & $3 / 1$ & $7 / 2$ & $4 / 1$ \\
\hline Sensitivity (HzL/mg) & 0.206 & 0.152 & 0.440 & 0.487 & 0.312 & 0.552 & 0.968 & 0.766 & 0.393 \\
\hline
\end{tabular}

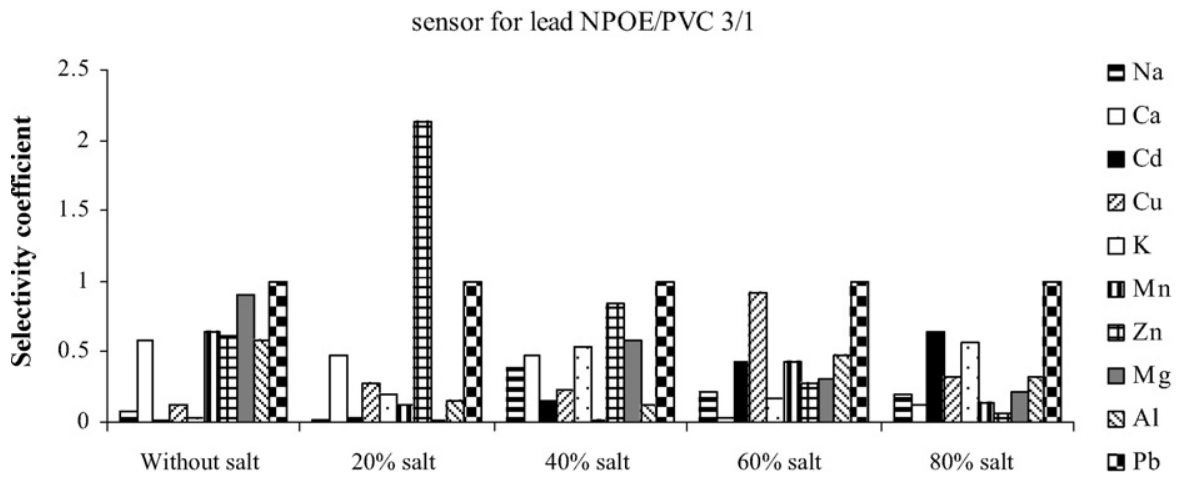

Fig. 2. Selectivity coefficients for the lead sensors.

sive additions of lead were performed, and changes in frequency of the quartz crystal recorded, until a lead concentration of $4.7 \mathrm{mg} / \mathrm{L}$ was achieved. $0.452 \mathrm{mg}$ of pig SC was then introduced into the glass cell and the frequency of vibration of the quartz crystal was followed. The lead absorption per unit of mass of skin was then computed. The skin was removed, and the lead solution was stored in a plastic bottle (sample A). The glass cell with the coated quartz crystal was then rinsed three times with Milli-Q water, after which $10 \mathrm{~mL}$ of Milli-Q water were again introduced into the glass cell, and kept undisturbed until constant frequency readings were obtained. The same skin piece, which has been in contact with the lead solution during the previous experiment, was then introduced into the Milli-Q water inside the glass cell, and the frequency of vibration of the quartz crystal was followed until a constant value was attained. Skin then removed from the cell and the liquid was kept in a plastic bottle (sample B).

All the glassware and plasticware were treated with $\mathrm{HNO}_{3}$ and rinsed first with distilled water and finally with Milli-Q water.

\section{Results and discussion}

According to Ye et al. [12] the amount of plasticizer changes the physical properties of the membrane, namely the stiffness and ductility and influences the mobility of species. In order to optimize the NPOE/PVC ratio for lead membranes, membranes with several NPOE/PVC ratios have been prepared. Table 1 shows the sensitivity to lead of the membranes vs. the ratio NPOE/PVC. In this case the NPOE/PVC ratio of 3/1 was found to produce the sensor with the highest sensitivity.

Besides the ionophore, PVC and plasticizer, selected amounts of potassium tetrakis ( $p$-chlorophenyl) borate were added to some of the membranes. Fig. 2 shows the selectivity coefficients for lead sensor against several possible interfering cations, cal- culated by the fixed interference method, for membranes with several salt/ionophore ratios.

Fig. 3 shows the frequency decrease for a piezoelectric quartz crystal coated with a membrane with a NPOE/PVC ration of $3 / 1$, and several salt compositions, observed with the addition of $\mathrm{Pb}^{2+}$ standards.

From Figs. 2 and 3 it is possible to observe changes in the selectivity and sensitivity with the amount of salt added to the membrane. Those results render possible to optimize the membrane composition according to the final use of the sensor and are of great value to other applications of this new lead sensor. As selectivity is not an issue in the present application of the sensor, the most sensitive membrane, the one without salt, was used throughout the work. Calibration of the sensor in the range between 0.947 and $4.73 \mathrm{mg} / \mathrm{L}$ of lead showed a linear relationship $\left(r^{2}=0.9997\right)$ between frequency decrease and $\mathrm{Pb}^{2+}$ concentration $\left(-\Delta F=12.26\left[\mathrm{~Pb}^{2+}\right]-1.800\right)$.

This sensor was used to follow lead sorption by pig SC. Fig. 4 shows the frequency change when $0.452 \mathrm{mg}$ of skin was inserted into the thermostated cell, in contact with a $4.73 \mathrm{mg} / \mathrm{L}$ lead solution. Lead remaining in the final solution was quantified by the

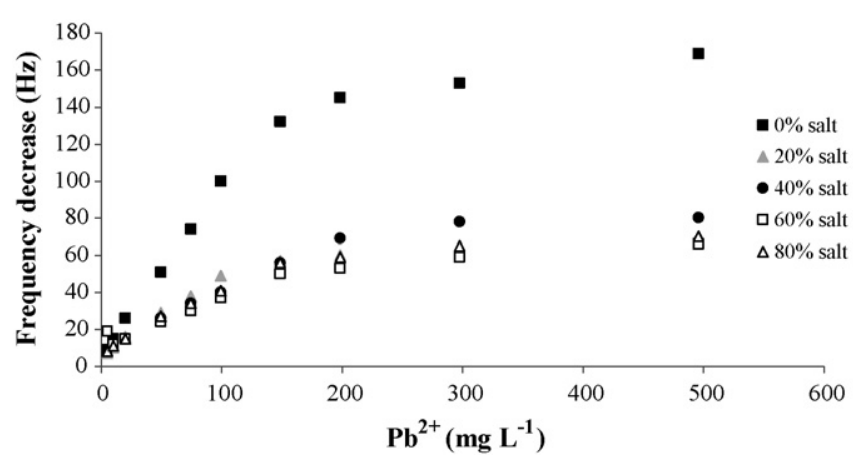

Fig. 3. Frequency decreases obtained with membranes with different salt/ionophore ratios. 


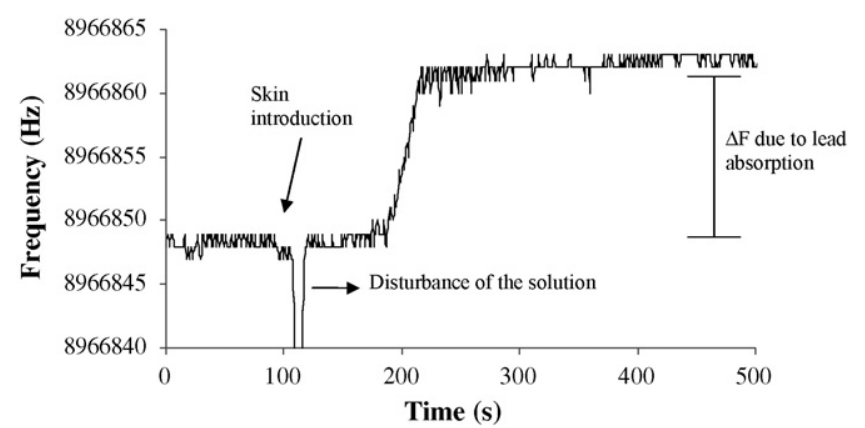

Fig. 4. Frequency of the quartz crystal before and after the addition of skin to the lead solution.

Table 2

Results obtained analyzing sample A and sample B using the bulk acoustic wave sensor (BAW) and atomic absorption spectrometer (AAS) (average of five determinations)

\begin{tabular}{lll}
\hline & $\mathrm{BAW} \mathrm{Pb}^{2+}(\mathrm{mg} / \mathrm{L})$ & $\mathrm{AAS} \mathrm{Pb}^{2+}(\mathrm{mg} / \mathrm{L})$ \\
\hline Sample A & $3.5 \pm 0.3$ & $3.5 \pm 0.1$ \\
Sample B & $1.3 \pm 0.4$ & $1.3 \pm 0.6$ \\
\hline
\end{tabular}

sensor, using the previous calibration line. Table 2 shows the $\mathrm{Pb}^{2+}$ concentration found in solution (average of five replicates).

The final solutions (solutions A) were also analysed by atomic absorption spectrometry. Calibration in the range between 0.50 and $6.0 \mathrm{mg} / \mathrm{L}$ in lead, obtained with an instrumental expansion factor of 4 , showed a linear relationship $\left(r^{2}=0.9983\right)$ between absorbance and $\mathrm{Pb}^{2+}$ concentration $\left(\mathrm{Abs}=0.0324\left[\mathrm{~Pb}^{2+}\right]-0.001\right)$. Results obtained by AAS are also shown in Table 2.

The amount of lead absorbed by the by the SC can be easily computed by the difference between the total lead added and the lead remaining in the final solution. The calculated lead absorption was $29.6 \mathrm{mg} \mathrm{Pb} / \mathrm{g}$ of stratum corneum.

Lead desorption from SC was also studied. Fig. 5 shows the frequency change observed with the addition of the same piece of SC to $10 \mathrm{~mL}$ of Milli-Q water. A medium frequency decrease of $15 \mathrm{~Hz}$ was obtained, which matches the value of frequency increase obtained in the absorption experiments, which is an indication that all the lead absorbed by the $\mathrm{SC}$ had been released. The liquid within the cell after the lead desorption was also analysed by AAS (sample B). New lead standards were needed for

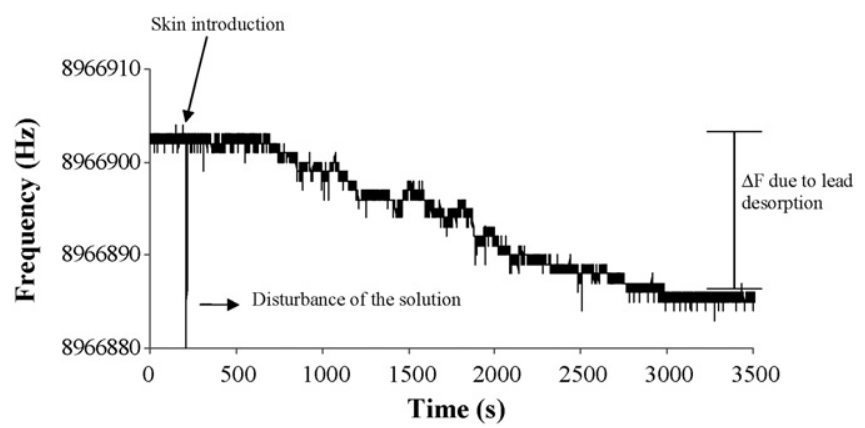

Fig. 5. Frequency of the quartz crystal before and after the addition of skin to Milli-Q water. the analysis as $\mathrm{Pb}^{2+}$ concentrations were very small. Therefore, a new calibration was performed in the range $0.400-1.75 \mathrm{mg} / \mathrm{L}$, an instrumental expansion factor of 6 was necessary, and a linear relationship $\left(r^{2}=0.9982\right)$ between absorbance and $\mathrm{Pb}^{2+}$ concentration $\left(\mathrm{Abs}=0.463\left[\mathrm{~Pb}^{2+}\right]+0.0056\right)$ was obtained.

Comparing the results obtained by the sensor and AAS methodologies analysing samples A and B, allowed to conclude that medium values were the same. The standard deviations were compared using an $F$-test. As the $F$ calculated values were less that the critical ones $(\alpha=0.05)$, no significant difference in the precision of both methodologies have been found.

The ability of the sensor to perform analysis in real time allowed to study the kinetics of lead desorption. The results obtained for lead desorption were consistent with a zero-order process.

\section{Acknowledgments}

This project was financed by the FCT, POCTI and FEDER.

\section{References}

[1] J.A. Bouwstra, P.L. Honeywell-Nguyen, G.S. Gooris, M. Ponec, Structure of the skin barrier and its modulation by vesicular formulations, Prog. Lipid Res. 42 (2003) 1-26.

[2] B. van Ravenzwaay, E. Leibold, The significance of in vitro rat skin absorption studies to human risk assessment, Toxicol. In Vitro 18 (2004) 219-225.

[3] W. Diembeck, H. Bekc, F. Benech-KIeffer, P. Courtellemonth, J. Dupuis, W. Lovell, M. Payne, M. Spengler, W. Steiling, Test guidelines for in vitro assessment of dermal absorption and percutaneous penetration of cosmetic ingredients, Food Chem. Toxicol. 37 (1999) 191-205.

[4] F.P. Schmook, J.G. Meingassner, A. Billich, Comparison of human skin or epidermis models with human and animal skin in in vitro percutaneous absorption, Int. J. Pharm. 215 (2001) 51-56.

[5] W. Horwitz (ed.), Lead (Method 935.50), seventeenth edition, Official methods of analysis of AOAC International, Gaithersburg MD, 2003.

[6] M. Casado, S. Daunert, M. Valiente, Lead-selective electrode based on a quinaldic acid derivative, Electroanalysis 13 (2001) 54-60.

[7] W. Yantasee, G.E. Fryxell, M.M. Conner, Y. Lin, Nanostructured electrochemical sensors based on functionalized nanoporous silica for voltammetric analysis of lead, mercury and copper, J. Nanosci. Nanotech. 5 (2005) 1537-1540.

[8] M. Ghiaci, B. Rezaei, R.J. Kalbasi, High selective $\mathrm{SiO}_{2}-\mathrm{AlO}_{3}$ mixedoxide modified carbon paste electrode for anodic stripping voltammetric determination of $\mathrm{Pb}(\mathrm{II})$, Talanta, in press.

[9] M.T.S.R. Gomes, Application of the piezoelectric quartz crystals to the analysis of trace metals in solution:a review, IEEE Sens. J. 1 (2001) $109-118$.

[10] J. Yin, W. Wei, X. Liu, B. Kong, L. Wu, S. Gong, Immobilization of bovine serum albumin as a sensitive biosensor for the detection of trace lead ion in solution by piezoelectric quartz crystal impedance, Anal. Biochem. 360 (2007) 99-104.

[11] M.T.S.R. Gomes, K.S. Tavares, J.A.B.P. Oliveira, The quantification of potassium using a quartz crystal microbalance, Analyst 125 (2000) 1983-1986.

[12] Q. Ye, S. Borbély, G. Horvai, Microstructure of ion-selective plasticized PVC membranes studied by small-angle neutron scattering, Anal. Chem. 71 (1999) 4313-4320.

\section{Biographies}

Marta I.S. Veríssimo has a post-doc position at the University of Aveiro. She received a BS degree in chemistry in 1998 from the University of Aveiro and 
a PhD in analytical chemistry in 2003 from the same University. Her current research interests are in chemical sensors and analytical chemistry.

Alberto A.C.C. Pais is an associate professor at the University of Coimbra. He received his BS degree in chemical engineering from the University of Coimbra in 1983, and a PhD in chemistry from the same University in 1993. His research interests include polyelectrolytes in solution, and skin structure and properties

João A.B.P. Oliveira is an associate professor at the University of Aveiro. He received his BS degree in chemical engineering from the Technical University of
Lisbon in 1976 and a $\mathrm{PhD}$ in analytical chemistry from the University of Virginia in 1985. His current research interests are chemical sensors, chemometrics, and laboratory automation.

M. Teresa S.R. Gomes is an associate professor at the University of Aveiro She received her BS degree in chemical engineering from the University of Coimbra in 1983 and a PhD in analytical chemistry from the University of Aveiro in 1997. Her current interests are chemical sensors and analytical chemistry. 